\title{
Root Canal Configuration of Permanent Mandibular First and Second Molars Using Radiographic Tube Shift Technique in Dental Hospital Patients at Faculty of Dentistry Universitas Sumatera Utara
}

\author{
Trelia Boel \\ Department of Oral Radiology \\ Faculty of Dentistry, Universitas Sumatera Utara \\ Medan, Indonesia \\ treliaboel@gmail.com
}

\author{
Dewi Kartika \\ Department of Oral Radiology \\ Faculty of Dentistry, Universitas Sumatera Utara \\ Medan, Indonesia \\ d_weex@yahoo.co.id
}

\author{
Dennis \\ Department of Conservative Dentistry \\ Faculty of Dentistry, Universitas Sumatera Utara \\ Medan, Indonesia \\ dennis_dionisius@yahoo.co.uk
}

\begin{abstract}
The knowledge of the pulp anatomy plays an important role in the success of endodontic treatments. Mandibular molars have been reported with complex configuration canal anatomical, making them one of the most difficult teeth to manage endodontically. The aim of this study was to examine the root canal morphology of mandibular molars using tube shift technique. This study was descriptive with cross sectional approach. A total of 40 patients of each 40 left and right on first and second molars were samples for this study. We used $x$-rays with tube shift technique to analyzed canal configuration. The number of canal configuration in each root based on Vertucci's classification was observed. Results showed root canal configuration of permanent first molars on

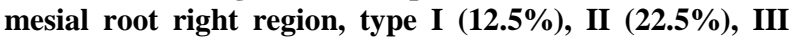
$(5 \%)$, IV $(57.5 \%)$, another type 3-2 (2.5\%), and left region type I (5\%), II (37.5\%), IV (52.5\%), V (2.5\%), another type 3-2 $(2.5 \%)$, and on distal root right region, type I $(87.5 \%)$, III (5\%), IV (2.5\%), V (5\%) and left region type I $(90 \%)$, II (5\%), III (2.5\%), V (2.5\%). Molars root canal configuration of permanent second molars on mesial root right region, type I (52.5\%), II (35\%), IV (12.5\%), and left region type I $(57.5 \%)$, II $(22.5 \%)$, III $(2.5 \%)$, IV $(12.5 \%)$, $\mathrm{V}(5 \%)$, and on distal root right region type I $(92.5 \%)$, II $(5 \%), \mathrm{V}(2.5 \%)$ and left region type I $(87.5 \%)$, II $(5 \%)$, IV $(2.5 \%)$, V $(5 \%)$. Mandibular permanent first and second molars based on Vertucci classification, both mesial and distal roots have found type I, II, III, IV, V, but on mesial roots permanent mandibular first molars have found another types 3-2.
\end{abstract}

Keywords-tube shift technique, root canal configuration, mandibular permanent molars

\section{INTRODUCTION}

Root canal treatment will succeed with adequate debridement and filling of the entire root canal system. One of the reasons of the failure in dental root canal treatment is lack of knowledge on the pulp anatomy and canal variation. The type of the normal anatomy of the pulp and the possible different changes in its anatomy should be known [1].

Mandibular first and second molars are the posterior teeth that are most prone to suffer from caries, leading to requirement of endodontic treatment. The anatomic configuration of roots and canals of mandibular first and second molars is diverse. The differences may be related to study design (in vivo vs. in vitro), technique of canal identification (radiographic examination, sectioning and clearing) or to racial divergence [2].

Periapical radiography is a common radiography that clinicians use for endodontic treatment. They inform the diagnosis and the various treatment phases and help evaluate the success or failure of treatment. But it is limited by the fact that information is rendered in only 2 dimensions. Although, in certain tooth groups, several different cone angulations are necessary in order to be able to overcome the superimposition of roots and canals which reflect the shape of the tooth in third dimension (tube shift technique) $[3,4]$.

\section{MATERIALS AND METHODS}

This is a descriptive research with a cross sectional approach. The research was conducted at the Radiology Unit from July to August 2017. The sample in this research was 40 patients from Faculty of Dentistry 
Universitas Sumatera Utara Dental Hospital. The samples were selected by purposive sampling. Criteria of inclusion in this study were 18-23 years who have right and left permanent mandibular first molars and second molars with perfectly formed roots. While the criteria of exclusion was the tooth with periapical lesions, root canals with open apical, resorption, or calcification, tooth with caries that has reached the pulp, tooth with root canal treatment, post and restoration of the crown and tooth with root fracture. All patients were informed about the study, about its risks and benefits, and signed an agreement concerning their participation.

Four images were made of each patient in two periapical technique, 2 periapical techniques with standard angulation to right and left mandibular first and second molars and 2 periapical technique with a variation of $30^{\circ}$ horizontal angulation distally (tube shift technique) to right and left mandibular first and second molars. A total of 160 images were obtained. Determination of root canal configuration was classified by Vertucci classification. All images were evaluated by two expert examiners, a dental radiologist and an endodontist. The data analysis presented in the form of frequency and percentage.

TABLE I. ROOT CANAL CONFIGURATION ACCORDING TO THE VERTUCCI CLASSFICATION [5]

\begin{tabular}{|l|l|}
\hline $\begin{array}{c}\text { Root canal } \\
\text { configuration }\end{array}$ & \multicolumn{1}{|c|}{ Description } \\
\hline Type I & $\begin{array}{l}\text { One root canal extending from the pulp chamber to } \\
\text { the apex }\end{array}$ \\
\hline Type II & $\begin{array}{l}\text { Separate root canals leave the pulp chamber and } \\
\text { join short of the apex to form one canal }\end{array}$ \\
\hline Type III & $\begin{array}{l}\text { One root canal leaves the pulp chamber before } \\
\text { dividing into two within the root, which then merge } \\
\text { to exit as a single canal }\end{array}$ \\
\hline Type IV & $\begin{array}{l}\text { Two separate root canals extend from the pulp } \\
\text { chamber to the apex }\end{array}$ \\
\hline Type V & $\begin{array}{l}\text { One root canal leaves the pulp chamber and divides } \\
\text { short of the apex into two separate and distinct } \\
\text { canals with separate apical foramina }\end{array}$ \\
\hline Type VI & $\begin{array}{l}\text { Two separate root canals leave the pulp chamber, } \\
\text { merge in the body of the root, and again divide } \\
\text { short of the apex to exit as two separate and distinct } \\
\text { canals }\end{array}$ \\
\hline Type VII & $\begin{array}{l}\text { One root canal leaves the pulp chamber, divides } \\
\text { and rejoins within the body of the root, and finally } \\
\text { redivides into two distinct canals short of the apex }\end{array}$ \\
\hline Type VIII & $\begin{array}{l}\text { Three separate and distinct root canals extend from } \\
\text { the pulp chamber to the apex }\end{array}$ \\
\hline
\end{tabular}

\section{RESULTS}

TABLE II. FREQUENCY DISTRIBUTIONS OF THE CONFIGURATIONS ACCORDING TO THE VERTUCCI'S CLASSIFICATION IN THE MANDIBULAR FIRST MOLARS

\begin{tabular}{|l|c|c|c|c|c|c|c|c|}
\hline \multirow{2}{*}{$\begin{array}{c}\text { Canal } \\
\text { Configuration }\end{array}$} & \multicolumn{3}{|c|}{ On Right Region (40) } & \multicolumn{3}{c|}{ On Left Region (40) } \\
\cline { 2 - 9 } & \multicolumn{2}{|c|}{ Mesial } & \multicolumn{2}{c|}{ Distal } & \multicolumn{3}{c|}{ Mesial } & \multicolumn{2}{|c|}{ Distal } \\
\cline { 2 - 9 } & $\mathbf{n}$ & $\mathbf{( \% )}$ & $\mathbf{n}$ & $\mathbf{( \% )}$ & $\mathbf{n}$ & $\mathbf{( \% )}$ & $\mathbf{n}$ & $\mathbf{( \% )}$ \\
\hline Type I & 5 & 12.5 & 35 & 87.5 & 2 & 5 & 36 & 90 \\
\hline Type II & 9 & 22.5 & 0 & 0 & 15 & 37.5 & 2 & 5 \\
\hline Type III & 2 & 5 & 2 & 5 & 0 & 0 & 1 & 2.5 \\
\hline Type IV & 23 & 57.5 & 1 & 2,5 & 21 & 52.5 & 0 & 0 \\
\hline Type V & 0 & 0 & 2 & 5 & 1 & 2.5 & 1 & 2.5 \\
\hline Type VI & 0 & 0 & 0 & 0 & 0 & 0 & 0 & 0 \\
\hline Type VII & 0 & 0 & 0 & 0 & 0 & 0 & 0 & 0 \\
\hline Type VIII & 0 & 0 & 0 & 0 & 0 & 0 & 0 & 0 \\
\hline $\begin{array}{l}\text { Another type } \\
(3-2)\end{array}$ & 1 & 2.5 & 0 & 0 & 1 & 2.5 & 0 & 0 \\
\hline
\end{tabular}

TABLE III. FREQUENCY DISTRIBUTIONS OF THE CONFIGURATIONS ACCORDING TO THE VERTUCCI'S CLASSIFICATION IN THE MANDIBULAR SECOND MOLARS

\begin{tabular}{|l|c|c|c|c|c|c|c|c|}
\hline \multirow{2}{*}{$\begin{array}{c}\text { Canal } \\
\text { Configuration }\end{array}$} & \multicolumn{3}{|c|}{ On Right Region (40) } & \multicolumn{3}{c|}{ On Left Region (40) } \\
\cline { 2 - 9 } & \multicolumn{2}{|c|}{ Mesial } & \multicolumn{2}{c|}{ Distal } & \multicolumn{2}{c|}{ Mesial } & \multicolumn{2}{c|}{ Distal } \\
\cline { 2 - 9 } & $\mathrm{n}$ & $(\%)$ & $\mathrm{n}$ & $(\%)$ & $\mathrm{n}$ & $(\%)$ & $\mathrm{n}$ & $(\%)$ \\
\hline Type I & 21 & 52.5 & 37 & 92.5 & 23 & 57.5 & 35 & 87.5 \\
\hline Type II & 14 & 35 & 2 & 5 & 9 & 22.5 & 2 & 5 \\
\hline Type III & 0 & 0 & 0 & 0 & 1 & 2.5 & 0 & 0 \\
\hline Type IV & 5 & 12.5 & 0 & 0 & 5 & 12.5 & 1 & 2.5 \\
\hline Type V & 0 & 0 & 1 & 2.5 & 2 & 5 & 2 & 5 \\
\hline Type VI & 0 & 0 & 0 & 0 & 0 & 0 & 0 & 0 \\
\hline Type VII & 0 & 0 & 0 & 0 & 0 & 0 & 0 & 0 \\
\hline Type VIII & 0 & 0 & 0 & 0 & 0 & 0 & 0 & 0 \\
\hline
\end{tabular}

\section{DISCUSSION}

The study of root canal anatomy is important for clinical dental practice and has immense anthropological significance. Different in vitro techniques have been described to evaluate root canal morphology, the most popular of which demineralization and staining of extracted teeth.

TABLE IV. COMPARISON OF FREQUENCY DISTRIBUTIONS (PERCENTAGES) OF CANAL CONFIGURATIONS IN THE MESIAL AND DISTAL ROOTS OF THE MANDIBULAR FIRST PERMANENT MOLARS IN THE PREVIOUS STUDIES

\begin{tabular}{|c|c|c|c|c|c|c|c|c|c|c|c|}
\hline \multirow[b]{2}{*}{ Study } & \multirow{2}{*}{$\begin{array}{l}\text { Race or } \\
\text { ethnicity }\end{array}$} & \multirow[b]{2}{*}{ Root } & \multicolumn{9}{|c|}{ Types of canal configuration } \\
\hline & & & I & II & III & IV & $\mathbf{v}$ & VI & VII & VIII & $\begin{array}{l}\text { Another } \\
\text { type }\end{array}$ \\
\hline Skidmore & Caucasian & $\mathrm{M}$ & 6.7 & 37.8 & - & 55.5 & - & - & - & - & \\
\hline et al [6] & & & 71.1 & 1 & - & 1.2 & - & - & - & - & - \\
\hline Pineda & Caucasian & M & 12 & & - & 0 & - & - & - & - & - \\
\hline Kuttler [7] & & D & 73.0 & 12.7 & - & 4.3 & & -8 & - & & - \\
\hline Vertucci & Caucasian & M & 12.0 & 28.0 & - & 51.0 & 8.0 & - & - & - & - \\
\hline & & D & 70.0 & 15.0 & - & 7.0 & 8.0 & & & & - \\
\hline Wasti et al. & Pakistani & M & & 23.0 & - & 67.7 & 0 & 6.0 & - & - & - \\
\hline & & & 30.0 & & & & 20 & 33 & - & & - \\
\hline Gulab & Burmese & & & 33 & 11.0 & 41.4 & 15.8 & 2.0 & - & & - \\
\hline & & & & & & & 13.8 & 2.0 & - & - & - \\
\hline Sert et al. & Turkish & $\mathrm{M}$ & 2. & 44.0 & 5.0 & 43.0 & 1.0 & - & - & - & - \\
\hline [11] & & D & 53.5 & 12.5 & 21.0 & 9.5 & 2.5 & - & - & - & - \\
\hline Ahmed et & Sudanese & M & & 14.0 & 1.0 & 73 & 1.0 & & - & - & - \\
\hline al. [1 & & D & 38 & 2 & 0 & 22 & 1.0 & 6.0 & - & & \\
\hline Rwenyonyi & Uganda & M & & 13.8 & 5.8 & 44.6 & 4.5 & 3.1 & - & - & - \\
\hline et al. [13] & & & & & 0.9 & & 2.7 & & & & \\
\hline Peiris [14] & Sri & $\mathrm{M}$ & & 26.5 & 3.7 & 57.3 & 2.0 & 2.0 & 0.3 & 1.0 & \\
\hline & Lankan & $D$ & 73.2 & 1.0 & 6.1 & 7.5 & 10.9 & 0.7 & 0.3 & & 0.3 \\
\hline & Japan & M & 2.6 & 34.2 & 2.6 & 44.8 & 5.3 & 2.6 & & 2.6 & 5.3 \\
\hline & & & 47.4 & & & 31.6 & 5.2 & 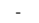 & - & & \\
\hline & Palestine & M & 1.15 & 38.8 & 1.9 & 53.8 & 1.15 & - & - & - & 3.2 \\
\hline & & D & 57.5 & 22.5 & 10.6 & 8.1 & 1.3 & & - & & \\
\hline
\end{tabular}

In the present study, we used horizontal tube shift technique that allowed three dimensions surveillance of the teeth. In this study it was found that 40 samples to assess the root canal configuration of the right and left mandibular first and second molars based on Vertucci classification. The number of the root canal configuration types for right mandibular first molars on mesial roots are, type IV $(57.5 \%)$, then type II $(22.5 \%)$, type I $(12.5 \%)$, type III (5\%), and another type that is type $3-2(2.5 \%)$, and for distal roots are, type I (87.5\%), type III (5\%), type V (5\%), and type IV (2.5\%). The root canal configuration types for left mandibular first molars on mesial roots are, type IV $(52.5 \%)$, type II $(37.5 \%)$, Type I (5\%), type V $(2.5 \%)$, and another type 3-2 $(2.5 \%)$, and for the distal roots are, type I (90\%), type II (5\%), type III (2.5\%), type V (2.5\%). The root canal configuration types for right mandibular second molars on mesial roots are, type I (52.5\%), type II (35\%), type IV $(12.5 \%)$ and for distal roots are type I (92.5\%), type II (5\%), type V $(2.5 \%)$. The root canal configuration types for left mandibular second molars on mesial roots are type I $(57.5 \%)$, type II $(22.5 \%)$, type 
IV (12.5\%), type V (5\%), type III (2.5\%), and for distal roots are type I $(87.5 \%)$, type II $(5 \%)$, type V (5\%), type IV $(2.5 \%)$. Some research has been done to see the root canal configuration for mandibular molars (Table IV).

Based on Table IV, the highest canal configuration for mandibular first molars, on mesial roots is type IV and distal roots are type I. Both right and left mandibular first molars, the types are similar to this research. But when compared with second molars, the percentage of canal configuration is varied. In this study, we found that the type I have a higher percentage both in right and left mandibular second molars. Other than that, we found types 3-2 (2.5\%) for mesial roots on right mandibular first molars, which was also found in studies by Peiriz et al and Mukhaimer et al.

TABLE V. COMPARISON OF FREQUENCY DISTRIBUTIONS (PERCENTAGES) OF CANAL CONFIGURATIONS IN THE MESIAL AND DISTAL ROOTS OF THE MANDIBULAR SECOND PERMANENT MOLARS IN THE PREVIOUS STUDIES

\begin{tabular}{|c|c|c|c|c|c|c|c|c|c|c|c|}
\hline \multirow[b]{2}{*}{ Study } & \multirow{2}{*}{$\begin{array}{l}\text { Race or } \\
\text { ethnicity }\end{array}$} & \multirow[b]{2}{*}{ Root } & \multicolumn{9}{|c|}{ Types of canal configuration } \\
\hline & & & I & II & III & IV & $\mathbf{v}$ & VI & VII & VIII & $\begin{array}{c}\text { Another } \\
\text { type }\end{array}$ \\
\hline Pineda\&Kuttler & Caucasian & $\mathrm{M}$ & 58 & 20.6 & - & 13.8 & 7.6 & 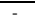 & - & - & \\
\hline & & D & 94 & 2.5 & - & 3.0 & 0.5 & - & - & 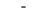 & 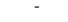 \\
\hline Vertucci $[8]$ & Caucasian & $\begin{array}{l}\mathrm{M} \\
\mathrm{D}\end{array}$ & $\begin{array}{l}27 \\
42\end{array}$ & $\begin{array}{c}38.0 \\
3.0\end{array}$ & - & $\begin{array}{c}26.0 \\
4.0\end{array}$ & $\begin{array}{l}9 \\
1\end{array}$ & : & : & : & : \\
\hline Gulabivala et al. & Burnese & $\mathrm{M}$ & 30.8 & 35.0 & 3.8 & 26.0 & 1.3 & - & - & - & - \\
\hline & & D & 80.7 & 5.1 & 1.3 & 1.3 & 1.3 & - & - & - & - \\
\hline Sert et al. [11] & Turkish & M & 12.5 & 31.5 & 21.5 & 28.0 & 2.0 & - & - & - & - \\
\hline & & D & 76.0 & 5.5 & 13.0 & 2.0 & 2.5 & & - & - & - \\
\hline Ahmed et al. & Sudanese & M & 5.0 & 18.0 & & 63.0 & 0 & 3.0 & - & 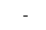 & - \\
\hline & & $D$ & 65 & 11.0 & - & 10.0 & 1.0 & 2.0 & 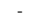 & - & - \\
\hline Rwenyonyi et al. & Uganda & M & 32.7 & 11.7 & 3.1 & 49.8 & 1.8 & 0.9 & - & & \\
\hline [13] & & D & 94.2 & & 1.3 & 2.7 & 0.9 & 0.4 & 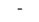 & 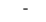 & 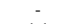 \\
\hline Peiris [14] & & M & 31.3 & 13.8 & 26.2 & 15.6 & 11.6 & 0.4 & - & - & 1.1 \\
\hline & Lankan & D & 96.4 & 0.3 & 1.1 & & 2.2 & - & - & - & \\
\hline & & M & 42.1 & 21.1 & 21.1 & 10.5 & - & - & - & - & 5.2 \\
\hline Subha et al. [15] & Japan & & & & & & & . & - & - & \\
\hline & & M & $\begin{array}{l}27.3 \\
88.8\end{array}$ & $\begin{array}{l}19.1 \\
27\end{array}$ & 2.7 & 48.2 & $\begin{array}{l}0.9 \\
0.9\end{array}$ & - & - & - & - \\
\hline
\end{tabular}

Clinically, periapical radiography is an adjunction to clinical examination in dentistry. It has an important role in the diagnosis of dental pathologies and treatment planning. Periapical radiography is a valuable diagnostic tool; its limitation is that it provides a 2 dimensional image of a 3-dimensional structure. However, its limitations may be aided by altering horizontal angulation toward the mesial or distal side to create a three dimensional structure. The technique is called tube shift technique (buccal object rule/same lingual, opposite buccal rule). In endodontic therapy it is imperative that clinician knows the spatial or buccolingual relation of an object within the tooth or alveolus. Proper application of the technique allows the dentist to locate additional canals or roots, to distinguish between objects that have been superimposed, and to distinguish between various types of resorption.

In conclusion, mandibular permanent first molars based on Vertucci classification, on mesial root right mandibular first molars have found type I, II, III, IV and another type (3-2), and on left found type I, II, IV, V and another type (3-2). On distal root right mandibular first molars have found type I, III, IV, V, and on left found type I, II, III, V. The root canal configuration on mesial root right mandibular second molars have found type I, II, and IV, and on left found I, II, III, IV, V. On distal roots right mandibular first molars have found type I, II, V and on left type I, II, IV, V.

\section{ACKNOWLEDGEMENT}

The authors are very grateful to all participants in this study. It was funded by Penelitian Talenta Universitas Sumatera Utara 2017.

\section{REFERENCES}

[1] J.M. Zare, G.F. Jafari, E.M. Mashhadi, Z.S.H. Moounavi, M. Sarami, "Root canal and morphology of mandibular second molars in an Iranian population by clearing method," J. Dent Shiraz Univ. Med. Scien., vol. 14(2), pp. 78-81, 2013.

[2] A.A. Al-Qudah, L.A. Awawdeh, Root canal and morphology of mandibular first and second molars teeth in a Jordanian population," IEJ., vol. 42, pp. 775-784, 2009.

[3] M.M. Bornstein, R. Lauber, P. Sendi, V.R. Thomas, "Comparison of periapical radiography and limited cone beam computed tomography in mandibular molars for analysis of anatomical landmark before apical surgery," J. Endod., vol. 37, pp. 151-157, 2011.

[4] M.R.R.S. Bardauli, C.M. Netto, A.M.M. de Moura, "Evaluation of the maxillary premolars roots dissociation using radiographic holders with conventional and digital radiography," Braz. Oral Res., vol. 24(3), pp. 284-289, July 2010.

[5] K.M. Hargreaves, L.H. Berman, I. Rotstein, Cohen's pathways of the pulp, $11^{\text {th }}$ ed., St. Louis: Elsevier.

[6] A.E. Skidmore, A.M. Bjorndal, "Root canal morphology of the human mandibular first molars," Oral Surg. Oral Med. Oral Pathol., vol. 32, pp.778-784, 1971.

[7] F. Pineda, Y. Kuttler, "Mesiodistal and buccolingual roentgenographic investigation of 7,275 root canals," Oral Surg Oral Med. Oral Pathol., vol. 33, pp. 101-110.

[8] F.J. Vertucci, "Root canal anatomy of human permanent teeth," Oral Surg. Oral Med. Oral Pathol., vol. 58, pp. 589-599, 1984.

[9] F. Wasti, A.C. Shearer, N.H.F. Wilson, "Root canal systems of the mandibular and maxillary first permanent molars teeth of South Asian Pakistanis," Int. Endod. J., vol. 34, pp. 263-266, 2001.

[10] K. Gulabivala, T.H. Aung, A. Alavi, Y.L. Ng, "Root and canal morphology of Burmese mandibular molars," Int. Endod. J., vol. 34, pp. 359-370, 2001.

[11] S. Sert, V. Aslanalp, J. Tanalp, "Investigation of root canal configurations of mandibular permanent teeth in the Turkish population,” Int. Endod. J., vol. 37, pp. 494-499, 2004.

[12] H.A. Ahmed, N.H. Abu-bakr, N.A. Yahia, Y.E. Ibrahim, "Root and canal morphology of permanent mandibular molars in a Sudanese population,” Int. Endod. J., vol. 40, pp. 766-771, 2007.

[13] C.M. Rwenyonyi, A.K.L.M. Muwazi, W. Buwembo, "Root and canal morphology of mandibular first and second permanent molars teeth in a Uganda population," Odontology, vol. 97, pp. 92-96, 2009.

[14] R. Peiris, "Root canal morphology of human permanent teeth in a Sri Lankan and Japanese population," Anthropological Science, vol. 116(2), pp. 123-133, 2008.

[15] R.H. Mukhaimer, "Evaluation of root canal configuration of mandibular first molars in a Palestinian population by using cone-beam computed tomography: An ex vivo study," Hindawi Publishing Corporation, vol. 13, pp. 1-6, August 2014.

[16] S.C. White, Oral radiology principles and interpretation, $7^{\text {th }}$ ed. Canada: Elsevier Mosby, 2014. 